\title{
Clinical and epidemiological characteristics of COVID-19 mortality in Saudi Arabia
}

Rawabi M. Alsayer, BHSc, Hassan M. Alsharif, FRCPc, ABIM, Abeer M. Al Baadani, MD, Kiran A. Kalam, MD.

\begin{abstract}

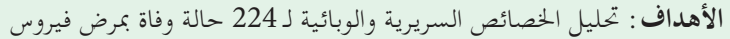

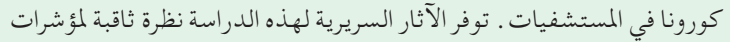

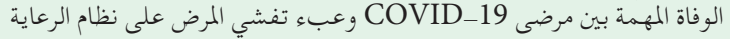
الصحية في المملكة العربية السعودية مانس

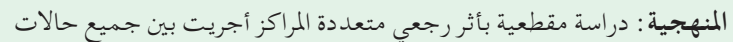

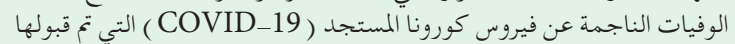

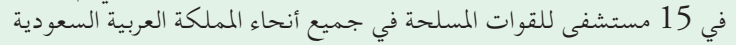

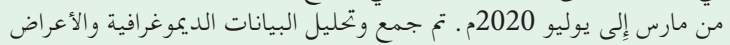

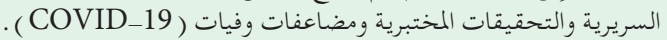

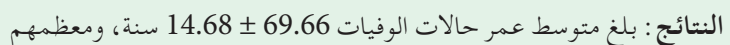

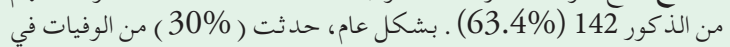

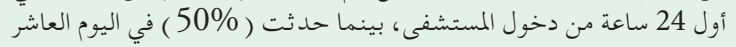

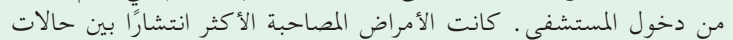

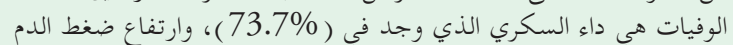

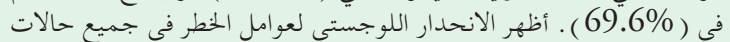

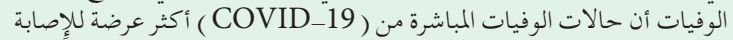

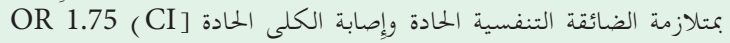
. 0.89-3.43 ) ـ p=0.102 ]، [ OR 1.01 (CI 0.54-1.90) p=0.960

الحلاصة : كانت الشيخوخة وجنس الذكور والانتشار المرتفع للأمراض الكامنة

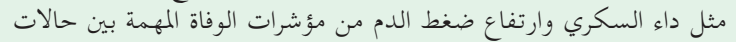

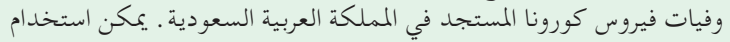

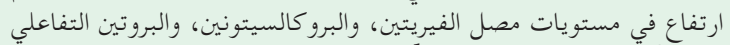

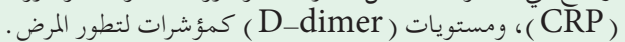

Objectives: To analyze the clinical and epidemiological characteristics for 224 of in-hospital coronavirus disease 2019 (COVID-19) mortality cases. This study's clinical implications provide insight into the significant death indicators among COVID-19 patients and the outbreak burden on the healthcare system in the Kingdom of Saudi Arabia (KSA).

Methods: A multi-center retrospective cross-sectional study conducted among all COVID-19 mortality cases admitted to 15 Armed Forces hospitals across KSA, from March to July 2020. Demographic data, clinical presentations, laboratory investigations, and complications of COVID-19 mortality cases were collected and analyzed.
Results: The mean age was $69.66 \pm 14.68$ years, and $142(63.4 \%)$ of the cases were male. Overall, $30 \%$ of the COVID-19 mortalities occurred in the first 24 hours of hospital admission, while $50 \%$ occurred on day 10 . The most prevalent comorbidities were diabetes mellitus (DM, 73.7\%), followed by hypertension (HTN, 69.6\%). Logistic regression for risk factors in all mortality cases revealed that direct mortality cases from COVID-19 were more likely to develop acute respiratory distress syndrome (odds ratio [OR]: 1.75, confidence intervel [CI: 0.89-3.43]; $p=0.102$ ) and acute kidney injury (OR: $1.01, \mathrm{CI}$ : [0.54-1.90]; $p=0.960$ ).

Conclusion: Aging, male gender and the high prevalence of the underlying diseases such as, DM and HTN were a significant death indicators among COVID-19 mortality cases in KSA. Increases in serum ferritin, procalcitonin, C-reactive protein (CRP), and D-dimer levels can be used as indicators of disease progression.

Keywords: Coronavirus, COVID-19, SARS-CoV-2, epidemiology, mortality, Saudi Arabia

Saudi Med J 2021; Vol. 42 (10): 1083-1094 doi: 10.15537/smj.2021.42.10.20210396

From the Scientific Research Center (Alsayer); from the Department of Infectious Disease (Al Baadani, Kalam), Prince Sultan Military Medical City, Riyadh, and from the Department of Intensive Care (Alsharif), King Fahad Armed Forces Hospital, Jeddah, Kingdom of Saudi Arabia.

Received 19th May 2021. Accepted 1st September 2021.

Address correspondence and reprint request to: Rawabi M. Alsayer, The Scientific Research Center, Prince Sultan Military Medical City, Riyadh, Kingdom of Saudi Arabia.E-mail: rm.alsayer@msd.med.sa ORCID ID: https://orcid.org/0000-0002-6153-2196

Disclosure. Authors have no conflict of interests, and the work was not supported or funded by any drug company. 
T The outbreak of disease caused by the severe acute respiratory syndrome corona virus-2 (SARS$\mathrm{CoV}-2$ ) has led to significant global morbidity and mortality since December 2019. It was declared as a pandemic by the World Health Organization (WHO) in March 2020, and by May 2020 there had been more than 5 million confirmed cases of coronavirus disease-19 (COVID-19) worldwide. ${ }^{1,2}$ The new strain of coronavirus was named SARS-CoV-2 as it originated from the identical family to the Middle East respiratory syndrome (MERS-CoV) and SARS-CoV-1 viruses. However, there has been limited knowledge of its virologic course and pathogenesis. ${ }^{1,3}$

During the initial phase of the COVID-19 outbreak, the disease's diagnosis was complicated by the diversity in symptoms and imaging findings (with some cases having no symptoms of fever or radiologic abnormalities) and the severity of disease at the time of presentation. ${ }^{4}$ Patient characteristics such as old age, male gender, chronic comorbidity, previous immunity, and virus mutations have consistently been associated with increased mortality. ${ }^{5,6}$ Evidence indicates that the COVID-19 mortality rate varies significantly across countries, from $>16 \%$ in France to $<0.1 \%$ in Singapore. This wide variation implies that several factors determine COVID-19 mortality, including hospital care and government response. ${ }^{6,7}$

In the Kingdom of Saudi Arabia (KSA), the Ministry of Health (MOH) reported the first case of COVID-19 in March 2020. As of December 2020, cumulative totals of 358,713 cases and 5,965 deaths had been reported in $\mathrm{KSA}^{8}{ }^{8}$ A national cross-sectional study describing the demographic and clinical characteristics of COVID-19 patients in KSA reported that nearly $20 \%$ had underlying comorbidities, with $8.8 \%$ having hypertension (HTN) and $7.6 \%$ having diabetes mellitus (DM). In total, $71.6 \%$ of patients were admitted to hospitals, $4.7 \%$ required intensive care unit (ICU) treatment, and $0.65 \%$ deaths. Although the mortality was less than 1\%; however, as reported, the study's clinical outcomes were not fully assessed. Further studies in the region are recommended to elaborate on severity predictions, and related risk factors for deterioration. ${ }^{9}$ There has been limited substantiation of the factors that determine COVID-19 burdens in the Middle East in general and in KSA in particular. The COVID-19 has placed unprecedented strain on healthcare systems, with rapidly increasing demands in hospitals and particularly in ICUs globally. Projecting and determining the future demand for healthcare resources (such as beds, staff, and equipment) has become a key priority for many countries as the pandemic has escalated. The present study aimed to fill this knowledge gap.

Data from epidemiological, clinical, and laboratory investigations of 224 cases of COVID-19 mortality was collected retrospectively and analyzed. Exploring the clinical and epidemiological factors associated with COVID-19 mortalities will add significantly to the body of knowledge, of the outbreak burden both in KSA and worldwide, particularly in terms of patient health and the healthcare system. The findings will provide insight into significant death indicators among COVID-19 cases, helping physicians to triage patients, identify those who are critically ill, and prioritize ICU admissions. Moreover, they will help to control and prevent the current outbreak, improve public health, and minimize the burden.

Methods. This descriptive, cross-sectional, multicenter retrospective study examined the clinical and epidemiological characteristics of COVID-19 mortality cases among patients admitted to Armed Forces Medical Services (MSD) hospitals across KSA. The current analysis included data on mortality cases reported at 15 MSD hospitals during the study period.

Respiratory samples (nasopharyngeal swab, sputum, or tracheal aspirate) were collected for COVID-19 laboratory screening using a polymerase chain reaction (PCR) test as per the protocol established by WHO. ${ }^{10}$ Confirmation of COVID-19 infection was based on a positive PCR result reported by either the National Health Laboratory or an MSD hospital laboratory. All mortality in cases with confirmed COVID-19 infections admitted to MSD hospitals between March and July 2020 with a complete MOH COVID-19 mortality data sheet were included in the study. Cases with unavailable or incomplete data were excluded.

Mortality case data was obtained from the MSD Center for Infection Prevention and Control (CIPC). The COVID-19 mortality data sheet initiated and developed by the Saudi MOH (updated in June 2020) included the following epidemiological and clinical characteristics: demographics, hospital name/location, symptoms, comorbidities, co-infections, laboratory data, level of care (ICU admission), full resuscitation (full code), or do-not-resuscitate (DNR), investigations (chest X-ray), and complications.

Laboratory data was collected and analyzed only from a single center, the Prince Sultan Military Medical City (PSMMC) in Riyadh, KSA, as they were not available from the other MSD hospitals. The PSMMC, Riyadh, KSA, is the biggest tertiary referral center. Trends in the following 6 biomarkers were included in the analysis: lymphocytes $(\times 109 / \mathrm{L})$; serum ferritin 
( $\mathrm{pmol} / \mathrm{L}) ;$ D-dimer $(\mathrm{mcg} / \mathrm{mL})$; serum creatinine (SCr, mol/L); C-reactive protein (CRP, $\mathrm{mg} / \mathrm{l}$ ); and procalcitonin $(\mathrm{mcg} / \mathrm{l})$. Data was collected on the day of presentation, at days 3-4, and 24-hours prior to death for all mortality cases $(n=115)$ admitted to the PSMMC, Riyadh, KSA.

To preserve the integrity and privacy of the data, all data was independently entered into a password-enabled electronic sheets and restricted to selected investigators. An identification number has been assigned to all participants. Ethical approval was obtained from the Central Research Ethics Committee of the Armed Forces Medical Services Scientific Research Center (approval number 2020-012). Informed consent was waived due to the retrospective and observational nature of the study. All methods were carried out according to applicable guidelines and regulations of the Declaration of Helsinki.

The main study outcomes analyzed were clinical characteristics, survival (time-to-death), and the correlation between case-fatality rate (CFR) and ICU bed-occupancy rate.

Survival (time-to-event) analysis can be used to determine the length of time until the occurrence of a well-defined endpoint of interest. Data was calculated and analyzed retrospectively from the date of hospital admission and receiving medical care until the date of death (in days) for each mortality case. Kaplan-Meier survival estimates were applied to analyze the time between ICU and general ward admission, DNR or full code, and death directly or indirectly caused by COVID-19.

The CFR in epidemiology is defined as the proportion of cases that die from a specified disease among all the individuals diagnosed with that disease over a certain period. High rates of CFR are indicative of relatively poor outcomes. ${ }^{11}$ First, the overall CFR of COVID-19 was calculated for all MSD hospitals included in this study across KSA (April-July 2020). Then the CFR was calculated for the top 6 MSD hospitals, KSA, in terms of COVID-19 mortality reporting stratified by month and the average ICU bed-occupancy rate. The 6 hospitals included in the calculation were located in Riyadh, Khamis Mushait, Taif, Al-Kharj, Jeddah, and Tabuk, KSA. The ICU bed-occupancy rate was calculated for each hospital.

Fever was defined as an oral temperature of $\geq 38^{\circ}$. 9,12 Death due to COVID-19 was defined as mortality resulting from a clinically compatible illness in confirmed positive cases with no clear alternative cause of death (namely, trauma), no period of full recovery from COVID-19 between illness and death, and no pre-existing conditions that could trigger a severe disease course (namely, cancer). As per WHO, cases were classified as direct when COVID-19 was the immediate cause of death and indirect when COVID-19 illness initiated the events leading to death. ${ }^{13}$ The clinical application of DNR, following study cases in KSA, referred to the use of cardiopulmonary resuscitative measures in the event of a cardiac or pulmonary deterioration or arrest. Anticipated death, COVID-19 patients who have one or more of these factors has been categorized to anticipated death: cardiovascular disease, diabetes, respiratory disease (including severe asthma), obesity, a history of haematological malignancy or recent other cancer, autoimmune conditions, kidney, liver, and neurological diseases. ${ }^{14}$ Oxygen saturation (SpO2), a SpO2<94\% in patients with COVID-19 are considered to have severe illness. ${ }^{15}$

Statistical analysis. All data were analyzed using descriptive and inferential statistics via Microsoft Excel 2016 and the Statistical Package for Social Sciences for Windows, version 25 (IBM Corp., Armonk, NY, USA). Descriptive statistics, including means and standard deviations, were calculated for continuous variables, that were normally distributed such as age. Non-normally distributed variables were represented by the medians. Categorical variables such as gender, symptoms, and comorbidities were presented as frequencies and percentages.

Inferential statistics, including the Chi-square test, were applied to compare groups according to the cause of death from COVID-19 (direct or indirect). T-tests were applied to compare the means of normally distributed variables between the groups. The Wilcoxon signed ranks test was applied to compare laboratory biomarker trends between the day of presentation and 24-hours prior death. Logistic regression was applied for the significant variables. The Kaplan-Meier estimator was used to present and analyze the time-to-death of hospitalized mortality cases and to compare groups (that is, direct and indirect, ICU and general ward, DNR and full code) in terms of time-to-death using the log-rank test. The results were presented as the odds ratio $(\mathrm{OR})$ and $95 \%$ confidence interval $(\mathrm{CI})$. A $p$-value of $<0.05$ was considered significant.

Results. Between March and July 2020, 224 (1.0\%) of the 21,078 patients with COVID-19 pneumonia died in MSD hospitals, KSA. Table 1 shows the demographic and epidemiological characteristics of the 224 COVID-19 mortality cases that were included in this study. The majority of the mortality cases, 115 (51.35\%), were admitted to Riyadh, 32 (14.3\%) were 
admitted to $\mathrm{Al}$ Kharj, and 18 (8.0\%) were admitted to Taif, KSA. Blood groups B (48.7\%) and O (30.4\%) were the most frequent among mortality cases.

Overall, 142 (63.4\%) of the cases were male, the mean age was $69.66 \pm 14.68$ years, and the mean length of hospital stay (LOS) was 10 (0-90) days. In terms of the level of care and admission to general wards or ICUs,

Table 1 - Baseline characteristics of coronavirus disease 2019 (COVID-19) mortality cases admitted to Armed Forces Medical Services (MSD) hospitals, Kingdom of Saudi Arabia, between March and July $2020(\mathrm{~N}=224)$.

\begin{tabular}{lc}
\hline Baseline characteristics & $\mathbf{n}(\%)$ \\
\hline Age (years), mean \pm SD & $69.66 \pm 14.68$ \\
Gender & \\
Male & $142(63.4)$ \\
Female & $82(36.6)$ \\
Nationality & \\
Saudi & $208(92.9)$ \\
Non-Saudi & $16(7.1)$ \\
Hospital location & \\
Riyadh & $115(51.3)$ \\
Al-Kharj & $32(14.3)$ \\
Taif & $18(8.0)$ \\
Jeddah & $14(6.3)$ \\
Tabuk & $11(4.9)$ \\
Madina Al Munnawarah & $7(3.1)$ \\
Dhahran & $7(3.1)$ \\
Khamis Mushait & $7(3.1)$ \\
Wadi Al Dawasir & $5(2.2)$ \\
Hafr Al Batin & $3(1.3)$ \\
Najran & $2(0.9)$ \\
Jizan & $2(0.9)$ \\
Jubail & $1(0.4)$ \\
Source of hospital admission & \\
Emergency room & \\
Intra-hospital transfer (from within) & $198(88.4)$ \\
Transfer from another hospital & $8(3.6)$ \\
Unknown & $7(3.1)$ \\
Smoker & $11(4.9)$ \\
Yes & \\
No & $12(5.4)$ \\
Not documented & $207(92.4)$ \\
Blood type & $5(2.2)$ \\
B & \\
O & $109(48.7)$ \\
A & $68(30.4)$ \\
AB & $35(15.6)$ \\
Rh factors & $12(5.4)$ \\
Positive & \\
Negative & \\
Cause of death from COVID-19 & \\
Direct & \\
Indirect & \\
Length of hospital stay (days), median & \\
(minimum - maximum) & \\
Total & \\
\hline & \\
\hline & \\
\hline & \\
\hline
\end{tabular}

$142(63.4 \%)$ of the COVID-19 mortality cases were admitted to the ICU, while $82(36.6 \%)$ were admitted to the general ward. Most of the mortality cases were intubated 156 (69.6\%), and the death was anticipated in $193(86.2 \%)$ of the cases (Table 1$)$.

The most common symptoms among cases on the day of presentation were shortness of breath in 165 $(73.7 \%)$, fever in $154(68.8 \%)$, and cough in 145 $(64.7 \%)$. In contrast, $113(50.4 \%)$ of the cases had desaturation $(\mathrm{SpO} 2<94 \%)$ on the day of presentation. Mortality cases were classified as having either a direct or an indirect cause of death from COVID-19: 164 $(73.2 \%)$ were direct and $60(26.8 \%)$ were indirect. Direct mortality cases had a significant presentation of symptoms (at the day of presentation), fever $(p=0.001)$, and cough $(p=0.018)$ compared to the indirect cohort $(p=0.031)$. Indirect mortality cases had a significant positive co-infection $(p<0.001)$ and transfusion history $(p<0.001$; Table 2).

Table 2 shows that no differences in chest $\mathrm{x}$-rays on the day of presentation were observed among direct and indirect mortality cases: $34.9 \%$ of the cases showed lung infiltrate/opacities, $32.2 \%$ had a bilateral chest infiltration, $29.2 \%$ with a pleural effusion, and only $3.7 \%$ had a normal chest $\mathrm{x}$-ray.

Comorbidities were reported in 217 cases, among which $143(63.8 \%)$ reported multiple comorbidities. Diabetes mellitus occurred in $165(73.7 \%)$ and HTN in 156 (69.6\%), which were the most common comorbidities, followed by chronic kidney failure in 56 $(25.0 \%)$ and coronary artery disease in 52 (23.2\%). Asthma was present in $24(10.7 \%)$ and chronic obstructive pulmonary disease (COPD) in 7 (3.1\%) of the cases. Table 2 shows that no differences in comorbidities were observed among direct and indirect mortality cases, except for a significant difference in the indirect cause of death from COVID-19 in dementia ( $p=0.001$; Table 2).

Table 2 show the major complications among the COVID-19 mortality cases. The most common major complications were acute respiratory distress syndrome in $150(72.8 \%)$, shock in $93(45.1 \%)$, acute kidney injury in 90 (43.7\%), and sepsis/septic shock in 78 $(37.9 \%)$. Eighteen of the cases had no documented major complications. There was a significant difference in the indirect cause of death from COVID-19 group in terms of both cardiogenic shock $(p=0.005)$ and shock $(p=0.010)$. The death was anticipated in 193 cases $(86.2 \%)$, and it was significantly higher among the direct cohort ( $p=0.040$; Table 2)

Table 3 illustrate the trends in biomarkers of COVID-19 mortality cases $(n=115)$ admitted to 
Saudi Arabia COVID-19 mortality ... Alsayer et al

Table 2 - Clinical and epidemiological characteristics of COVID-19 mortality cases admitted to MSD hospitals, Kingdom of Saudi Arabia, between March and July 2020, stratified by cause of death from COVID-19 (N=224).

\begin{tabular}{|c|c|c|c|c|}
\hline Clinical characteristics & Direct $(n=164)$ & $\begin{array}{c}\text { Indirect }(n=60) \\
n(\%)\end{array}$ & Total $(\mathrm{N}=224)$ & $P$-value ${ }^{*}$ \\
\hline Age, mean \pm SD & $70.32 \pm 14.17$ & $67.87 \pm 16.00$ & $69.66 \pm 14.68$ & $0.365^{\ddagger}$ \\
\hline DNR & $75(45.7)$ & $33(55.0)$ & $108(48.2)$ & 0.219 \\
\hline Full code & $89(54.3)$ & $27(45.0)$ & $116(51.8)$ & \\
\hline Resuscitated & $84(51.2)$ & $25(41.7)$ & $109(48.7)$ & 0.205 \\
\hline Intubated & $114(69.5)$ & $42(70.0)$ & $156(69.6)$ & 0.944 \\
\hline Any symptoms $s^{\S}$ & $158(97.5)$ & $52(86.7)$ & $210(94.6)$ & $0.001^{\dagger \dagger}$ \\
\hline \multicolumn{5}{|l|}{ Symptoms* } \\
\hline $\begin{array}{l}\text { Shortness of breath } \\
\text { Fever } \\
\text { Cough } \\
\text { Confusion } \\
\text { Diarrhea } \\
\text { Chest pain }\end{array}$ & $\begin{array}{c}125(76.2) \\
120(73.2) \\
113(68.9) \\
21(12.8) \\
9(5.5) \\
11(6.7)\end{array}$ & $\begin{array}{c}40(66.7) \\
34(56.7) \\
32(53.3) \\
11(18.3) \\
8(13.2) \\
1(1.7)\end{array}$ & $\begin{array}{l}165(73.7) \\
154(68.8) \\
145(64.7) \\
32(14.3) \\
17(7.6) \\
12(5.4)\end{array}$ & $\begin{array}{c}0.151 \\
0.018^{\dagger \dagger} \\
0.031^{\dagger \dagger} \\
0.295 \\
0.050 \\
0.138\end{array}$ \\
\hline Desaturation $(\mathrm{SpO} 2<94 \%)^{* *}$ & $87(53.0)$ & $26(43.3)$ & $113(50.4)$ & 0.198 \\
\hline \multicolumn{5}{|l|}{ PPD/QuantiFERON test } \\
\hline $\begin{array}{l}\text { Positive } \\
\text { Negative } \\
\text { Total }\end{array}$ & $\begin{array}{c}16(10.7) \\
133(89.3) \\
149(100.0)\end{array}$ & $\begin{array}{c}11(19.6) \\
45(80.4) \\
56(100.0)\end{array}$ & $\begin{array}{c}27(13.2) \\
178(86.8) \\
205(100.0)\end{array}$ & 0.201 \\
\hline \multicolumn{5}{|l|}{ Chest $X$-ray ${ }^{\sigma_{1}^{* *}}$} \\
\hline $\begin{array}{l}\text { Normal } \\
\text { Bilateral infiltration } \\
\text { Infiltrate/opacities } \\
\text { Pleural effusion } \\
\text { Total }\end{array}$ & $\begin{array}{c}12(3.4) \\
114(32.5) \\
122(34.8) \\
103(29.3) \\
351(100.0)\end{array}$ & $\begin{array}{c}6(4.5) \\
42(31.6) \\
47(35.3) \\
38(28.6) \\
133(100.0)\end{array}$ & $\begin{array}{c}18(3.7) \\
156(32.2) \\
169(34.9) \\
141(29.2) \\
484(100.0)\end{array}$ & 0.957 \\
\hline Transfusion history & 37 (22.6) & $29(48.3)$ & $66(29.5)$ & $<0.001^{\dagger \dagger}$ \\
\hline $\begin{array}{l}\text { Type of transfusion history } \\
\text { PRBCs } \\
\text { FFP } \\
\text { Cryoprecipitate } \\
\text { Platelets } \\
\text { Intravenous immunoglobulin } \\
\text { Total }\end{array}$ & $\begin{array}{c}32(45.1) \\
15(21.1) \\
8(11.3) \\
10(14.1) \\
6(8.5) \\
71(100.0)\end{array}$ & $\begin{array}{c}25(45.5) \\
15(27.3) \\
3(5.5) \\
8(14.5) \\
4(7.3) \\
55(100.0)\end{array}$ & $\begin{array}{c}57(45.2) \\
30(23.8) \\
11(8.7) \\
18(14.3) \\
10(7.9) \\
126(100.0)\end{array}$ & 0.793 \\
\hline Was death anticipated? & $146(89.0)$ & $47(78.3)$ & $193(86.2)$ & $0.040^{\dagger \dagger}$ \\
\hline \multicolumn{5}{|l|}{ COVID-19 PCR at time of death } \\
\hline $\begin{array}{l}\text { Positive } \\
\text { Negative } \\
\text { Total }\end{array}$ & $\begin{array}{c}138(89.6) \\
16(10.4) \\
179(100.0)\end{array}$ & $\begin{array}{c}41(77.4) \\
12(22.6) \\
28(100.0)\end{array}$ & $\begin{array}{c}179(86.5) \\
28(13.5) \\
207(100.0)\end{array}$ & $0.032^{\dagger \dagger}$ \\
\hline \multicolumn{5}{|l|}{ Co-morbidities } \\
\hline $\begin{array}{l}\text { Diabetes } \\
\text { Hypertension } \\
\text { Chronic kidney failure } \\
\text { Coronary artery disease } \\
\text { Heart failure } \\
\text { Asthma } \\
\text { Multiple sclerosis } \\
\text { Atrial fibrillation } \\
\text { On dialysis } \\
\text { Ischemic stroke } \\
\text { Thyroid dysfunction } \\
\text { Dementia } \\
\text { COPD } \\
\text { Obesity }\end{array}$ & $\begin{array}{c}122(74.4) \\
117(71.3) \\
40(24.4) \\
39(23.8) \\
16(9.8) \\
19(11.6) \\
19(11.6) \\
14(8.5) \\
14(8.5) \\
13(7.9) \\
11(6.7) \\
4(2.4) \\
6(3.7) \\
3(1.8)\end{array}$ & $\begin{array}{l}43(71.7) \\
39(65.0) \\
16(26.7) \\
13(21.7) \\
9(15.0) \\
5(8.3) \\
4(6.7) \\
8(13.3) \\
3(5.0) \\
3(5.0) \\
5(8.3) \\
8(13.3) \\
1(1.7) \\
2(3.3)\end{array}$ & $\begin{array}{l}165(73.7) \\
156(69.6) \\
56(25.0) \\
52(23.2) \\
25(11.2) \\
24(10.7) \\
23(10.3) \\
22(9.8) \\
17(7.6) \\
16(7.1) \\
16(7.1) \\
12(5.4) \\
7(3.1) \\
5(2.2)\end{array}$ & $\begin{array}{c}0.682 \\
0.361 \\
0.728 \\
0.740 \\
0.270 \\
0.486 \\
0.283 \\
0.285 \\
0.376 \\
0.451 \\
0.676 \\
0.001^{\dagger \dagger} \\
0.448 \\
0.500\end{array}$ \\
\hline \multicolumn{5}{|l|}{ Co-infection } \\
\hline $\begin{array}{l}\text { Positive } \\
\text { Negative } \\
\text { Total }\end{array}$ & $\begin{array}{c}37(23.1) \\
123(76.9) \\
160(100.0)\end{array}$ & $\begin{array}{c}27(46.6) \\
31(53.4) \\
58(100.0)\end{array}$ & $\begin{array}{c}64(29.4) \\
154(70.6) \\
218(100.0)\end{array}$ & $<0.001^{\dagger \dagger}$ \\
\hline
\end{tabular}


Table 2 - Clinical and epidemiological characteristics of COVID-19 mortality cases admitted to MSD hospitals, Kingdom of Saudi Arabia, between March and July 2020, stratified by cause of death from COVID-19 ( $\mathrm{N}=224)$ (continued).

\begin{tabular}{|c|c|c|c|c|}
\hline Clinical characteristics & Direct $(n=164)$ & $\begin{array}{c}\text { Indirect }(\mathrm{n}=60) \\
\mathrm{n}(\%)\end{array}$ & Total & $P$-value ${ }^{*}$ \\
\hline \multicolumn{5}{|l|}{ If co-infection positive } \\
\hline $\begin{array}{l}\text { Bacterial } \\
\text { Fungal } \\
\text { Viral } \\
\text { Total }\end{array}$ & $\begin{array}{c}19(47.5) \\
4(10.0) \\
17(42.5) \\
40(100.0)\end{array}$ & $\begin{array}{c}17(65.4) \\
3(11.5) \\
6(23.1) \\
26(100.0)\end{array}$ & $\begin{array}{c}36(54.5) \\
7(10.6) \\
23(34.8) \\
66(100.0)\end{array}$ & 0.186 \\
\hline \multicolumn{5}{|l|}{ Complications ${ }^{\sqrt{ }}$} \\
\hline $\begin{array}{l}\text { ARDS } \\
\text { Shock } \\
\text { Acute kidney injury } \\
\text { Sepsis/septic shock } \\
\text { Secondary infections } \\
\text { Cardiogenic shock } \\
\text { Heart failure } \\
\text { Acute cardiac injury } \\
\text { Total }\end{array}$ & $\begin{array}{c}116(75.8) \\
61(39.9) \\
67(43.8) \\
54(35.3) \\
20(13.1) \\
6(3.9) \\
7(4.6) \\
11(7.2) \\
153(100.0)\end{array}$ & $\begin{array}{c}24(64.2) \\
32(60.4) \\
23(43.4) \\
24(45.3) \\
9(17.0) \\
8(15.1) \\
6(11.3) \\
1(1.9) \\
53(100.0)\end{array}$ & $\begin{array}{c}150(72.8) \\
93(45.1) \\
90(43.7) \\
78(37.9) \\
29(14.1) \\
14(6.8) \\
13(6.3) \\
12(5.8) \\
206(100.0)\end{array}$ & $\begin{array}{c}0.100 \\
0.010^{\dagger \dagger} \\
0.960 \\
0.196 \\
0.481 \\
0.005^{\dagger \dagger} \\
0.082 \\
0.155\end{array}$ \\
\hline
\end{tabular}

COVID-19: coronavirus disease-19, MSD: Armed Forces Medial Services, DNR: do-not-resuscitate, PPD/QuantiFERON: Purified protein derivative/ QuantiFERON, PRBCs: packed red blood cells, FFP: fresh frozen plasma, PCR: polymerase chain reaction, COPD: chronic obstructive pulmonary disease, ARDS: acute respiratory distress syndrome. ${ }^{*}$ Chi-square test, ${ }^{\ddagger}$ T-test. ${ }^{\circledR}$ Reported one or more co-infection, chest X-ray, type of transfusion history and complications, ${ }^{* *}$ at day of presentation. ${ }^{\dagger \dagger} p<0.05$ was considered significant

PSMMC, Riyadh, KSA. Coronavirus disease-19 trends in biomarkers were observed on the day of presentation, at day 3-4, and 24-hours prior to death. The serum ferritin ( $\mathrm{pmol} / \mathrm{L})$ level increased (Z-value $=-2.898$; $p=0.004$ ) between the day of presentation to 24-hours prior to death. The procalcitonin $(\mathrm{mcg} / \mathrm{l})$ level also increased ( $Z$-value $=-2.864 ; p=0.004$ ) between the day of presentation and 24-hours prior to death. The $\mathrm{D}$-dimer $(\mathrm{mcg} / \mathrm{mL})$ level significantly increased $(Z$-value $=-5.71$; $p<0.001)$ between the day of presentation and 24-hours prior to death (Table 3).

Logistic regression for risk factors in all mortality cases with COVID-19 revealed that the death being anticipated was 2 times more likely among cases classified as direct deaths. Cases with a history of COPD were twice as likely to die directly from COVID-19 (Table 4).

Predictors for COVID-19 mortality cases admitted to the ICU using logistic regression for risk factors revealed that the death being anticipated was 3 times more likely among ICU cases (OR: 3.26, 95\% CI: [1.11-13.16]; $\quad p=0.033)$. Coronavirus disease-19 mortality cases with a history of co-infection were twice as likely to be admitted to the ICU (OR: 2.94, 95\% CI: [1.47-5.85]; $p=0.002$ ). Cases with male gender (OR: 1.92, 95\% CI: [0.99-1.03]; $p=0.002$ ), older age (OR: $1.01,95 \%$ CI: [0.99-1.03]; $p=0.270]$, were also more likely to be admitted to the ICU (Table 4).
The overall CFR of COVID-19 at MSD hospitals across KSA (April-July 2020) was: Khamis Mushait (CFR: 4.30\%), Al-Kharj (CFR: 3.87\%), Dhahran hospitals (CFR: 2.22\%, 3.33\%), Taif hospitals (CFR: 0.93\%, 3.67\%), Riyadh (CFR: 1.51\%), Madinah (CFR: 1.46\%), Wadi Al Dawasir (CFR: 1.16\%), Tabuk (CFR: 0.87\%), Hafr Al Batin (CFR: 0.84\%), Jubail (CFR: 0.63\%), Jeddah (CFR: 0.41\%), Jizan (CFR: $0.37 \%$ ), and Najran (CFR: $0.30 \%$ ).

Figure 1 shows the CFR of COVID-19 stratified by month and the average ICU bed-occupancy rate between April and July 2020 at MSD hospitals in Riyadh, Khamis Mushait, Taif, Al-Kharj, Jeddah, and Tabuk, KSA. There was a correlation between the COVID-19 CFR increasing and the average ICU bedoccupancy rate in Riyadh hospital from May to July 2020 (CFR: $1.10 \%, 1.16 \%$, and $2.54 \%$, respectively) and the ICU bed-occupancy rate $(110 \%, 130 \%$, and $150 \%$, respectively). This was also seen in Al-Kharj hospital (CFR: $2.70 \%, 3.77 \%$, and 4.27\%, respectively; ICU bed-occupancy rate: $110 \%, 130 \%$, and $150 \%$, respectively) between April and July 2020.

Overall, $30 \%$ of the COVID-19 mortalities ( $N=224)$ occurred in the first 24-hours of hospitalization, while $50 \%$ occurred on day 10 of admission. The survival analysis of COVID-19 mortality cases showed a significant difference between the direct and indirect 
Table 3 - Biomarker trends of Coronavirus disease-19 mortality cases (at day of presentation, day 3-4, and 24-hours prior to death) admitted to PSMMC hospital between March and July 2020 ( $N=115)$.

\begin{tabular}{lcccc}
\hline Trends biomarker & \multicolumn{2}{c}{ Median (minimum - maximum) } & $P_{\text {-value* }}^{*}$ \\
& Day of presentation & Day (3-4) & 24-hours prior to death & \\
\hline Lymphocytes $\left(\times 10^{\ddagger} / \mathrm{L}\right)$ & $0.9(0.0-5.3)$ & $0.8(0.0-10.5)$ & $0.9(0.0-7.9)$ & 0.182 \\
Serum ferritin $(\mathrm{pmol} / \mathrm{L})$ & $686(37-9164)$ & $832(54-19864)$ & $1081(15-30356)$ & $0.004^{\dagger}$ \\
D-dimer $(\mathrm{mcg} / \mathrm{mL})$ & $1.53(0.18-20.0)$ & $1.83(0.30-20.0)$ & $3.81(0.11-20.0)$ & $<0.001^{\dagger}$ \\
Serum creatinine $(\mathrm{mol} / \mathrm{L})$ & $104(18-1220)$ & $117(15-978)$ & $172(19-1627)$ & 0.059 \\
C-reactive protein $(\mathrm{mg} / \mathrm{l})$ & $90(1-359)$ & $76(2-429)$ & $99(5-385)$ & 0.478 \\
Procalcitonin $(\mathrm{mcg} / \mathrm{l})$ & $0.4(0.05-59.0)$ & $0.05(0.05-57.0)$ & $1.2(0.03-99.3)$ & $0.004^{\dagger}$ \\
\hline
\end{tabular}

PSSMC: Prince Sultan Military Medical City, ${ }^{*}$ Wilcoxon signed ranks test. ${ }^{\dagger} p<0.05$ was significant. ${ }^{*}$ The day 3-4 and 24 -hours prior to death comparison had some missing values due to a number of the patients dying before they reached this stage.

Table 4 - Logistic regression for risk factors in direct mortality cases and cases admitted to ICUs with COVID-19 (N=224).

\begin{tabular}{lcccc}
\hline Variable & \multicolumn{1}{c}{ Direct death } & & ICU admission \\
& OR $(95 \%$ CI $)$ & $P$-value & OR (95\% CI) & $P$-value \\
\hline Age & $0.98(0.97-1.00)$ & 0.270 & $1.01(0.99-1.03)$ & 0.270 \\
Gender: male & $0.91(0.49-1.68)$ & 0.763 & $1.92(1.09-3.37)$ & $0.022^{\dagger}$ \\
Resuscitated & $1.47(0.80-2.67)$ & 0.206 & $0.99(0.57-1.71)$ & 0.978 \\
Death was anticipated & $2.24(1.02-4.92)$ & $0.044^{\dagger}$ & $3.26(1.493-7.14)$ & $0.003^{\dagger}$ \\
Desaturation (SpO2 <94\%) & $1.47(0.81-2.68)$ & 0.199 & $1.77(1.02-3.06)$ & 0.042 \\
Co-infection & $0.34(0.18-0.651)$ & $0.001^{\dagger}$ & $2.94(1.47-5.85)$ & $0.002^{\dagger}$ \\
Comorbidities: COPD & $2.24(0.26-19.00)$ & 0.460 & $0.42(0.09-1.92)$ & 0.265 \\
Complications & & & \\
$\quad$ ARDS & $1.75(0.89-3.43)$ & 0.102 & $2.02(1.07-3.80)$ & $0.029^{\dagger}$ \\
Acute kidney injury & $1.01(0.54-1.90)$ & 0.960 & $1.87(1.03-3.40)$ & $0.039^{\dagger}$ \\
Shock & $0.43(0.23-0.82)$ & $0.011^{\dagger}$ & $2.72(1.47-5.01)$ & $0.001^{\dagger}$ \\
Sepsis/septic & $0.65(0.34-1.24)$ & 0.198 & $2.92(1.52-5.60)$ & $0.001^{\dagger}$ \\
Secondary infections & $0.73(0.31-1.73)$ & 0.482 & $2.85(1.03-7.84)$ & $0.042^{\dagger}$ \\
Cardiogenic shock & $0.23(0.07-0.69)$ & $0.009^{\dagger}$ & $3.36(0.73-15-.47)$ & 0.119 \\
\hline ICUs: intensive care units, COVID-19: coronavirus disease -19, COPD: chronic obstructive pulmonary disease, ARDS: acute \\
\multicolumn{2}{l}{ respiratory distress syndrome, OR: odds ratio, CI: confidence interval } \\
\hline
\end{tabular}

cause of death from COVID-19 in the survival $(p=0.012)$ and the cases admitted to ICUs or general wards $(p<0.001)$. However, there were no significant differences in the survival analysis of COVID-19 mortality cases (DNR - full code; $p=0.525$; Figure 2).

Discussion. All of the laboratory-confirmed COVID-19 mortality cases admitted to MSD hospitals across regions of KSA between March and July 2020 were included in this study. The mean age was $69.66 \pm 14.68$ years, which is in between the figures reported from Pakistan and European population namely Italy and Spain $56.6 \pm 78$ years. ${ }^{16,17}$ This variation might be attributed to the differences in the population age group density. A recent meta-analysis that screened 516 studies showed that 43 studies from 12 countries reported a significant variation in the clinical characteristics in patients with COVID-19 globally. The in-hospital COVID-19 related mortality was higher amongst the elderlies in the United States of America (USA) and Europe as compared to Asia. ${ }^{18}$ The study data confirmed the fact that advanced age is one of the independent risk factors of mortality. Death was also significantly higher in males, as described in other studies. ${ }^{16,19}$

In contrary to the other parts of the world our deceased patients had blood group B (48.7\%) followed by $\mathrm{O}(30.4 \%){ }^{20,21} \mathrm{~A}$ study by Adiah et $\mathrm{al},{ }^{22}$ found groups $\mathrm{AB}$ and $\mathrm{B}+$ to be significantly associated with an increased risk of evolving COVID-19 and an increased 
Saudi Arabia COVID-19 mortality ... Alsayer et al

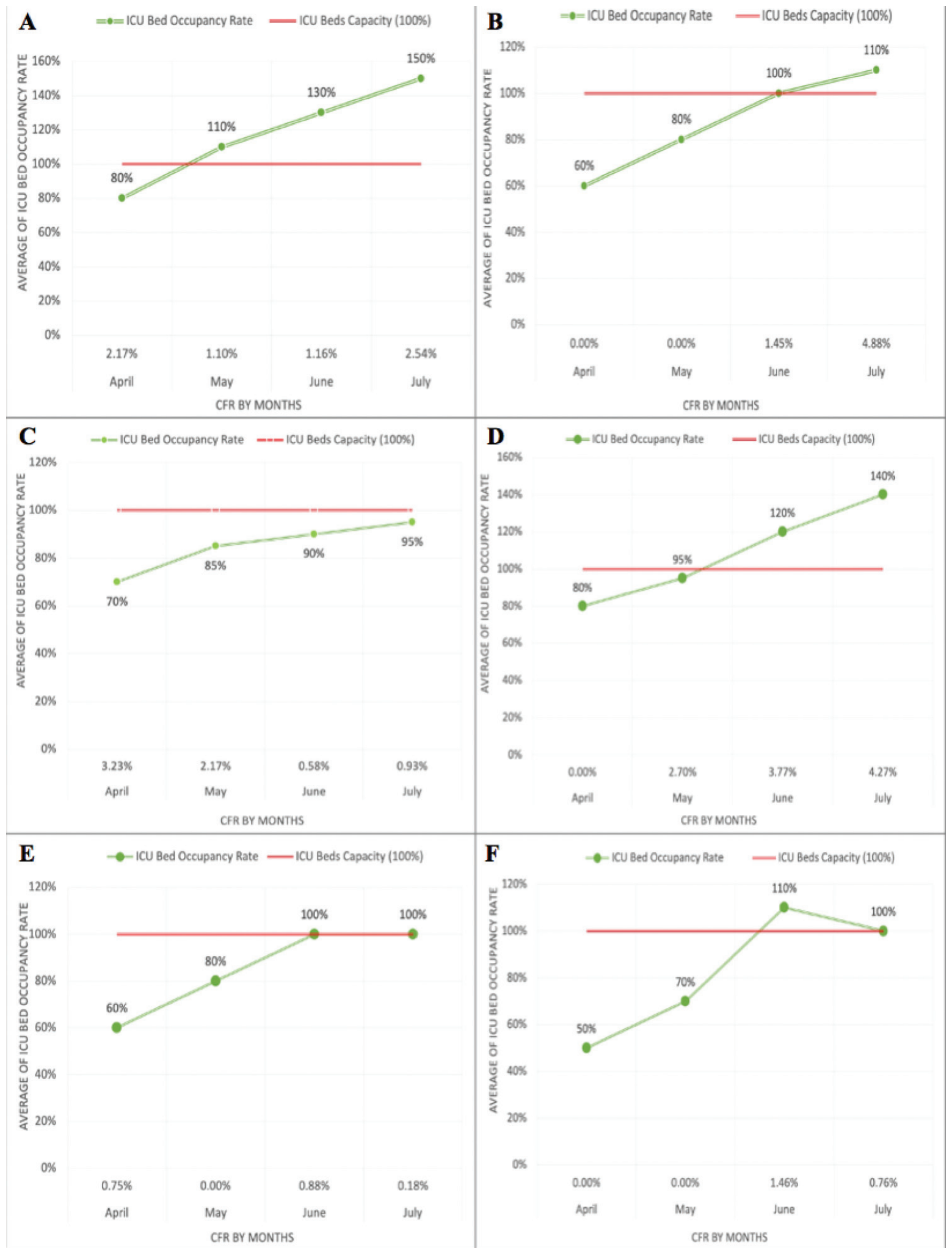

Figure 1 - Case fatality rate (CFR) of coronavirus disease- 2019 stratified by month and the average intensive care unit (ICU) bed occupancy rate, for the highest 6 cities in Kingdom of Saudi Arabia between April and July 2020. A) Riyadh, B) Khamis Mushait, C) Taif, D) Al-Kharj, E) Jeddah, and F) Tabuk. 
A

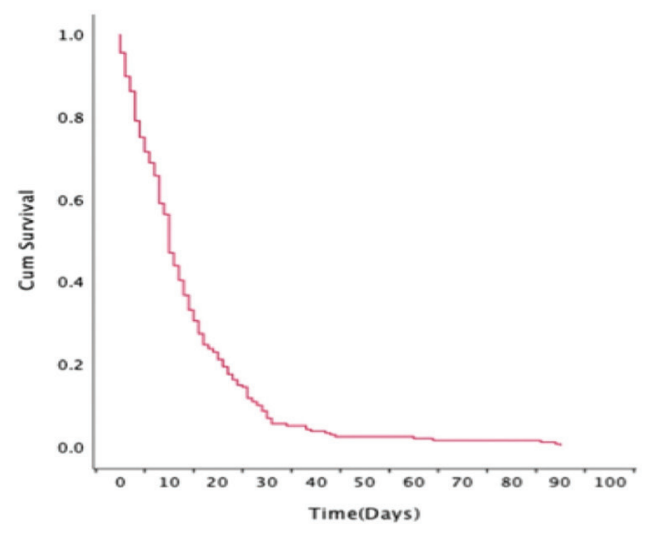

C

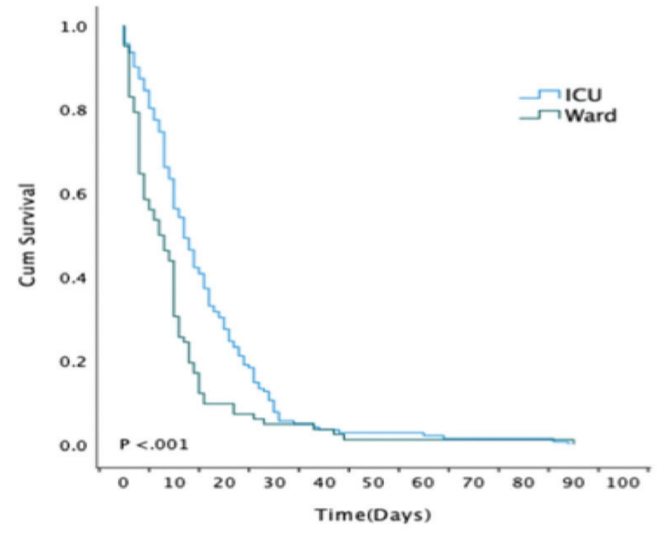

B

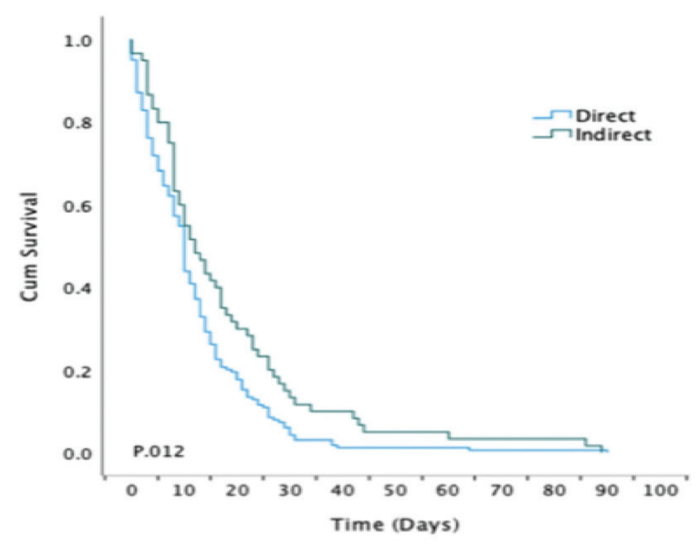

D

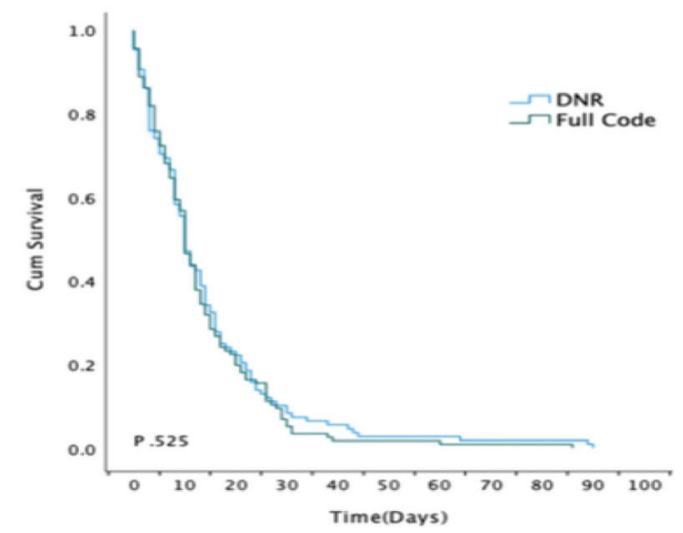

Figure 2 - Kaplan-Meier analysis of survival (time-to-death) of coronavirus disease- 2019 (COVID-19) mortality cases. A) Analysis of survival of all COVID-19 mortality cases. B) Coronavirus disease- 2019 mortality cases stratified by (direct - indirect) as a cause of death. C) Coronavirus disease- 2019 mortality cases stratified by intensive care unit (ICU)/general ward admission. D) Coronavirus disease- 2019 mortality cases stratified by (do-not-resuscitate [DNR] - Full Code).

risk of death among cases. A meta-analysis by Pourali, ${ }^{23}$ stated blood group A individuals were at a higher risk of COVID-19 infection; however, those with blood group $\mathrm{O}$ were at a lower risk.

Consistent with previous reports, the most common comorbidities among the mortality cases in our study were DM (73.7\%) and HTN (69.6\%). ${ }^{16-24}$ Diabetes mellitus is highly correlated with COVID-19 related deaths. ${ }^{5,25}$ It was reported to increase the risk of death 2-fold in a meta-analysis by Kumar et al. ${ }^{26}$ This pattern of associations is consistent with those found in the death records of more than 17 million COVID-19 cases from the National Institute for Health Research (NIHR). ${ }^{14}$

Indeed individuals with COPD are at risk of severe COVID-19. Our data revealed that cases with COPD had a 2-fold greater mortality risk irrespective to the preceded long acting inhaled steroids exposure. Notably, the protective role of long acting inhaled steroids has failed to be asserted in open safely platform date from England. ${ }^{27}$

Provided the differences in the prevalence of obesity globally, some data have suggested that it is an underlying risk factor for COVID-19 mortality, similar to the situation with Swine flu (H1N1). ${ }^{28}$ However, in our cohort only $2.2 \%$ of the mortality cases had preexisting obesity.

In line with a recent report, a clear burden of COVID-19 infection and multiple organ dysfunction was observed in the lungs, heart, and kidneys. ${ }^{29}$ Acute respiratory distress syndrome (ARDS) was the main direct COVID-19-related complication. As a result of 
progressive inflammatory and thrombogenesis cascades, substantial indirect complications have been noted; in particular, cardiac injury was reported in 19.7\% of cases in the Chinese cohort. ${ }^{30}$ Acute respiratory distress syndrome secondary to COVID-19 pneumonia has been the most frequent complication reported in case series. Diffuse alveolar damage is the primary event, followed by thrombotic microangiopathy, and some severe cases end up in a state of disseminated intravascular coagulation (DIC) without any evidence of bacterial superinfection. Dilated pulmonary vessels are a frequent finding in ARDS that is secondary to COVID in contrast to ARDS that is secondary to other causes. $^{31}$

Different ranges of co-infection have been reported from different parts of the world. ${ }^{32} \mathrm{~A}$ recent metanalysis by Lansbury et $\mathrm{al},{ }^{33}$ stated that $14 \%$ of cases had bacterial co-infection among COVID-19 patients admitted to the ICU. Postmortem data showed that up to $37 \%$ of COVID-19 deaths had pulmonary histopathological data consistent with superimposed bacterial pneumonia. ${ }^{34}$

To detect biochemical indicators that are significant for the disease progression, the laboratory test results of all the mortality cases from the PSMMC hospital, Riyadh, KSA, $(n=115)$ were included in this study. Though having a larger data set would offer further insight. In line with a recent report, rises in serum ferritin, procalcitonin, CRP, and D-dimer levels were indicators of disease progression. ${ }^{29}$ C-reactive protein and high blood urea nitrogen were associated with cytokine release syndrome and driven increased mortality in a study from France. ${ }^{35}$ In our current study, rising ferritin, D-dimer, and procalcitonin levels were associated with mortality. Most inflammatory markers are acute phase reactants that are not specific for severe COVID-19-related pneumonia. Qin et $\mathrm{al},{ }^{36}$ found a significant association between increased CRP and severe prognosis of the disease. Variable studies have shown that the D-dimer is an effective predictor for COVID-19 mortality. Its role in acute infections and thrombogenic states has been established previously. ${ }^{37}$ Asghar et $\mathrm{al}^{38}{ }^{38}$ reported that lactate dehydrogenase, D-dimer, procalcitonin, and ferritin have roles in predicting the severity of COVID-19 pneumonia.

The current study revealed a notable longitudinal association of the ICU bed occupancy and the fatality rate in all hospitals, with the highest rate of bed occupancy being in Riyadh, KSA, which is the capital city and has the largest population. Its hospital is the biggest tertiary referral center from all other MSD hospitals, KSA, and it had a fatality rate of $2.54 \%$. However, the highest fatality rate was observed in the Southern Region hospital (Khamis Mushait city), KSA, where it reached $4.88 \%$ because their ICU bed occupancy had increased by $10 \%$ above their capacity. Notably, the Western region hospitals represented by Taif and Jeddah, KSA, seemed to cope with the pandemic, with an adequate ICU bed occupancy that matched their capacity (95\% in Taif and $100 \%$ in Jeddah) alongside a lower fatality rate $(0.93 \%$ in Taif and $0.18 \%$ in Jeddah). Correlations between mortality and healthcare burden have been reported previously from China and different parts of the world. ${ }^{39,40}$

The study findings suggested that the main cause of mortality in COVID-19 was attributed either to acute respiratory failure or to acute thrombosis. Patients with comorbidities were at higher risk for contracting COVID-19, and some laboratory tests could predict disease progression and death: the serum ferritin, procalcitonin, CRP, and D-dimer levels could be used as indicators of disease progression.

Study limitations. First, the design was retrospective. Second, some cases had incomplete data on laboratory tests and complications, due to variation in the electronic database structure across different MSD hospitals, KSA. Third, there was a lack of proper disease-severity scoring. Fourth, although the study was multi-center, the number of mortalities was small; therefore, future studies with larger sample sizes are needed.

In conclusion, aging, male gender and the high prevalence of the underlying diseases such as, DM and HTN were observed as significant death indicators among COVID-19 mortality cases in KSA. Multiple organ dysfunction was observed, with the most common organ damage being to the lungs, heart, and kidneys. Rises in serum ferritin, procalcitonin, CRP, and D-dimer levels can be used as indicators of disease progression.

This study highlighted the significant burden of the COVID-19 outbreak, particularly in terms of patients' health and the healthcare system. The clinical implications provide insight into the major death indicators among COVID-19 patients in KSA. These medical and clinical indicators may help physicians to triage patients, identify those who are critically ill, and prioritize ICU admissions.

Acknowledgment. The authors gratefully acknowledge the support provided by Dr. Ali Albarrak, throughout this project. We would also like to thank Cambridge Proofreading LLC (www.proofreading.org) for English language editing. 


\section{References}

1. Ministry of Health. COVID-19 coronavirus disease guidelines [Internet]. Saudi CDC; 2020 [Updated 2020; Accessed 2020 Jun 03]. Available from: https://www.moh.gov.sa/Ministry/ MediaCenter/Publications/Documents/Coronavirus-Disease2019-Guidelines-v1.2.pdf

2. World Health Organization. Clinical management of severe acute respiratory infection when novel coronavirus ( $\mathrm{nCoV}$ ) infection is suspected. [Updated 2020. Accessed 2020 Aug 20]. Available from: https://www.who.int/publications/i/ item/10665-332299

3. World Health Organization. Report of the WHO-China Joint Mission on Coronavirus Disease 2019 (COVID-19). [Updated 2020. Accessed 2020 Jun 06]. Available from: https://www. who.int/publications/i/item/report-of-the-who-china-jointmission-on-coronavirus-disease-2019-(covid-19)

4. Guan WJ, Ni ZY, Hu Y, Liang WH, Ou CQ, He JX, et al. Clinical characteristics of coronavirus disease 2019 in China. $N$ Engl J Med 2020; 382: 1708-1720.

5. Docherty AB, Harrison EM, Green CA, Hardwick HE, Pius R, Norman L, et al. Features of 20133 UK patients in hospital with covid-19 using the ISARIC WHO clinical characterisation protocol: prospective observational cohort study. BMJ 2020; 369: $\mathrm{m} 1985$.

6. Liang LL, Tseng CH, Ho HJ, Wu CY. Covid-19 mortality is negatively associated with test number and government effectiveness. Sci Rep 2020; 10: 12567.

7. Chen T, Wu D, Chen H, Yan W, Yang D, Chen G, et al. Clinical characteristics of 113 deceased patients with coronavirus disease 2019: retrospective study. BMJ 2020; 368: m1091.

8. Ministry of Health. Information about COVID-19 Coronavirus in Saudi Arabia. [Updated 2020; Accessed 2020 Jun 9] Available from: https://www.moh.gov.sa/en/Ministry/ MediaCenter/Publications/Pages/covid19.aspx

9. Alsofayan YM, Althunayyan SM, Khan AA, Hakawi AM, Assiri AM. Clinical characteristics of COVID-19 in Saudi Arabia: a national retrospective study. J Infect Public Health 2020; 13: 920-925.

10. World Health Organization. WHO Coronavirus disease (COVID-19) technical guidance: Laboratory testing for 2019-nCoV in humans. [Updated 2020. Accessed 2020 Sep 06] Available from: https://www.who.int/emergencies/diseases/ novel-coronavirus-2019/technical-guidance-publications

11. Harrington RA. Case fatality rate. Encyclopedia Britannica. [Updated 2020 May 5; Accessed 2020 Sep 06] Available from: https://www.britannica.com/science/case-fatality-rate

12. Ryan M, Levy MM. Clinical review: fever in intensive care unit patients. Crit Care 2003; 7: 221-225.

13. World Health Organization. International guidelines for certification and classification (coding) of COVID-19 as cause of death. Based on ICD International Statistical Classification of Diseases. [Updated 2020 April 16; Accessed 2020 Jul 04] Available from: https://www.who.int/classifications/icd/ Guidelines_Cause_of_Death_COVID-19.pdf

14. Williamson EJ, Walker AJ, Bhaskaran K, Bacon S, Bates C, Morton CE, et al. Factors associated with COVID-19-related death using OpenSAFELY. Nature 2020; 584: 430-436.

15. NIAID-RML. Coronavirus disease 2019 (COVID-19) treatment guidelines [updated 2020; Accessed 2020 Jul 09]. Available from: https://www.covid19treatmentguidelines.nih. gov/
16. Shahid R, Umar M, Zafar RB, Zeb S, Ambreen S, Akram MO. Comorbidity of COVID-19 related fatalities in tertiary care hospitals of Rawalpindi, Pakistan. J Rawalpindi Med Coll 2020; 24 .

17. Biagi A, Rossi L, Malagoli A, Zanni A, Sticozzi C, Comastri G, et al. Clinical and epidemiological characteristics of 320 deceased patients with COVID-19 in an Italian Province: a retrospective observational study. J Med Virol 2020; 92: 2718-2724.

18. Goel S, Jain T, Hooda A, Malhotra R, Johal G, Masoomi R, et al. Clinical characteristics and in-hospital mortality for COVID-19 across the globe. Cardiol Ther 2020; 9: 553-559.

19. Berenguer J, Ryan P, Rodríguez-Baño J, Jarrín I, Carratalà J, Pachón J, et al. Characteristics and predictors of death among 4035 consecutively hospitalized patients with COVID-19 in Spain. Clin Microbiol Infect 2020; 26: 1525-1536.

20. Hultström M, Persson B, Eriksson O, Lipcsey M, Frithiof R, Nilsson B. Blood type A associates with critical COVID-19 and death in a Swedish cohort. Crit Care 2020; 24: 496.

21. Zietz M, Zucker J, Tatonetti NP. Associations between blood type and COVID-19 infection, intubation, and death. Nat Commun 2020; 11 : 5761.

22. Ad'hiah AH, Allami RH, Mohsin RH, Abdullah MH, AL-Sa'ady AJR, Alsudani MY. Evaluating of the association between ABO blood groups and coronavirus disease 2019 (COVID-19) in Iraqi patients. Egypt J Med Hum Genet 2020.

23. Pourali F, Afshari M, Alizadeh-Navaei R, Javidnia J, Moosazadeh M, Hessami A. Relationship between blood group and risk of infection and death in COVID-19: a live meta-analysis. New Microbes New Infect 2020; 37: 100743.

24. Grasselli G, Greco M, Zanella A, Albano G, Antonelli M, Bellani $G$, et al. Risk factors associated with mortality among patients with COVID-19 in intensive care units in Lombardy, Italy. JAMA Intern Med 2020; 180: 1345-1355.

25. Garg S, Kim L, Whitaker M, O’Halloran A, Cummings C, Holstein $\mathrm{R}$, et al. Hospitalization rates and characteristics of patients hospitalized with laboratory-confirmed coronavirus disease 2019 - COVID-NET, 14 states, March 1-30, 2020. MMWR Morb Mortal Wkly Rep 2020; 69: 458-464.

26. Kumar A, Arora A, Sharma P, Anikhindi SA, Bansal N, Singla V, et al. Is diabetes mellitus associated with mortality and severity of COVID-19? A meta-analysis. Diabetes Metab Syndr 2020; 14: 535-545.

27. Schultze A, Walker AJ, MacKenna B, Morton CE, Bhaskaran $\mathrm{K}$, Brown JP, et al. Risk of COVID-19-related death among patients with chronic obstructive pulmonary disease or asthma prescribed inhaled corticosteroids: an observational cohort study using the OpenSAFELY platform. Lancet Respir Med 2020; 8: 1106-1120.

28. Dietz W, Santos-Burgoa C. Obesity and its implications for COVID-19 mortality. Obesity (Silver Spring) 2020; 28: 1005.

29. Li X, Wang L, Yan S, Yang F, Xiang L, Zhu J, et al. Clinical characteristics of 25 death cases with COVID-19: a retrospective review of medical records in a single medical center, Wuhan, China. Int J Infect Dis 2020; 94: 128-132.

30. Shi S, Qin M, Shen B, Cai Y, Liu T, Yang F, et al. Association of cardiac injury with mortality in hospitalized patients with COVID-19 in Wuhan, China. JAMA Cardiol 2020; 5: 802-810. 
31. Gibson PG, Qin L, Puah SH. COVID-19 acute respiratory distress syndrome (ARDS): clinical features and differences from typical pre-COVID-19 ARDS. Med J Aust 2020; 213: 54-56.

32. Lai CC, Wang CY, Hsueh PR. Co-infections among patients with COVID-19: the need for combination therapy with nonanti-SARS-CoV-2 agents? J Microbiol Immunol Infect 2020; 53: 505-512.

33. Lansbury L, Lim B, Baskaran V, Lim WS. Co-infections in people with COVID-19: a systematic review and meta-analysis. J Infect 2020; 81: 266-275.

34. Calabrese F, Pezzuto F, Fortarezza F, Hofman P, Kern I, Panizo A, et al. Pulmonary pathology and COVID-19: lessons from autopsy. The experience of European pulmonary pathologists. Virchows Arch 2020; 477: 359-372.

35. Oussalah A, Gleye S, Urmes IC, Laugel E, Barbé F, Orlowski S, et al. The spectrum of biochemical alterations associated with organ dysfunction and inflammatory status and their association with disease outcomes in severe COVID-19: a longitudinal cohort and time-series design study. EClinicalMedicine 2020; 27: 100554 .
36. Qin C, Zhou L, Hu Z, Zhang S, Yang S, Tao Y, et al. Dysregulation of immune response in patients with coronavirus 2019 (COVID-19) in Wuhan, China. Clin Infect Dis 2020; 71 : 762-768.

37. Zhou F, Yu T, Du R, Fan G, Liu Y, Liu Z, et al. Clinical course and risk factors for mortality of adult inpatients with COVID-19 in Wuhan, China: a retrospective cohort study. Lancet 2020; 395: 1054-1062.

38. Asghar MS, Haider Kazmi SJ, Khan NA, Akram M, Hassan M, Rasheed U, et al. Poor prognostic biochemical markers predicting fatalities caused by COVID-19: a retrospective observational study from a developing country. Cureus 2020; 12: e9575.

39. Ji Y, Ma Z, Peppelenbosch MP, Pan Q. Potential association between COVID-19 mortality and health-care resource availability. Lancet Glob Health 2020; 8: e480.

40. Bambra C, Riordan R, Ford J, Matthews F. The COVID-19 pandemic and health inequalities. I Epidemiol Community Health 2020; 74: 964-968. 